during an influenza epidemic. We have shown, however, that subunit vaccine is well tolerated by asthmatic patients and is immunogenic.

We thank Miss Dee Smith and Mr A Freke for valuable laboratory help and Mrs Peters, Mrs Williams, and Mrs Cook for typing the manuscript. We are grateful to Duphar Laboratories Ltd for their help and financial support.

1 Oulette JJ, Reed CE. Increased response of asthmatic subjects to methacholine after influenza vaccine. J Allengy 1965;36:558-63.

2 Bachmayer $H$. Selective solubilisation of haemagglutinin and neuraminidase from influenza viruses. Intervirology 1975;5:260-8.

3 Barry DW, Mayner RE, Hockstein HD, et al. Comparative trial of influenza vaccines. II. Adverse reactions in children and adults. Am F Epidemiol 1976;104:47-59.

4 Cockcroft DW, Killian DN, Mellon JJ, Hargreave FE. Bronchial reactivity to inhaled histamine: a method and clinical survey. Clin Allergy 1977;7:235-43.

5 Grilli EA, Smith AJ. The use of a radial haemolysis test for neuraminidase antibodies in the diagnosis of influenza A infection. $\mathcal{F}$ Hyg (Camb) 1983;91:147-56.

(Accepted 13 February 1987)

Ham Green Hospital, Pill, Bristol BS20 0AY

M K ALBAZZAZ, MB, MRCP, medical resgistrar

J E HARVEY, MD, MRCP, consultant physician

Influenza Research Unit, Public Health Laboratory, St Luke's Hospital, Guildford GU1 3NT

E A GRILLI, PHD, FIMLS, principal microbiologist

Regional Public Health and District Virology Laboratory, Bristol BS2 8EL E O CAUL, PHD, FIMLS, top grade microbiologist

A P ROOME, MB, FRCPATH, consultant virologist

Correspondence to: Dr J E Harvey.

\section{Acute mesenteric ischaemia caused by Schistosoma mansoni infection}

Symptoms of the three types of schistosomiasis reflect the particular venous system infested by the parasitic ova. Infestation of the pelvic vein explains the bladder and rectal symptoms of schistosomiasis haematobia, schistosomiasis mansoni, which is prevalent in north east Africa and parts of the Middle East, predominantly affects the inferior mesenteric vein, and the oriental parasite Schistosoma japonicum has a predilection for the superior mesenteric vein and is therefore most likely to affect the small intestine. Intestinal obstruction may result from an intussuscepting polypoid mass or from fibrotic stenosis of the lower wall. ${ }^{1}$

We report a rare case of infestation with $S$ mansoni, in which mesenteric venous occlusion led to acute obstruction and infarction of the jejunum.

\section{Case report}

A 35 year old Egyptian man presented to Yarmouk Hospital, Baghdad, in June 1985 with the clinical and radiological features of high small bowel obstruction. The absence of bowel sounds, tachycardia ( 115 beats $/ \mathrm{min})$, and abdominal tenderness suggested a diagnosis of strangulation. He was dehydrated and had a blood pressure of $90 / 60 \mathrm{~mm} \mathrm{Hg}$. Five years earlier he had undergone splenectomy

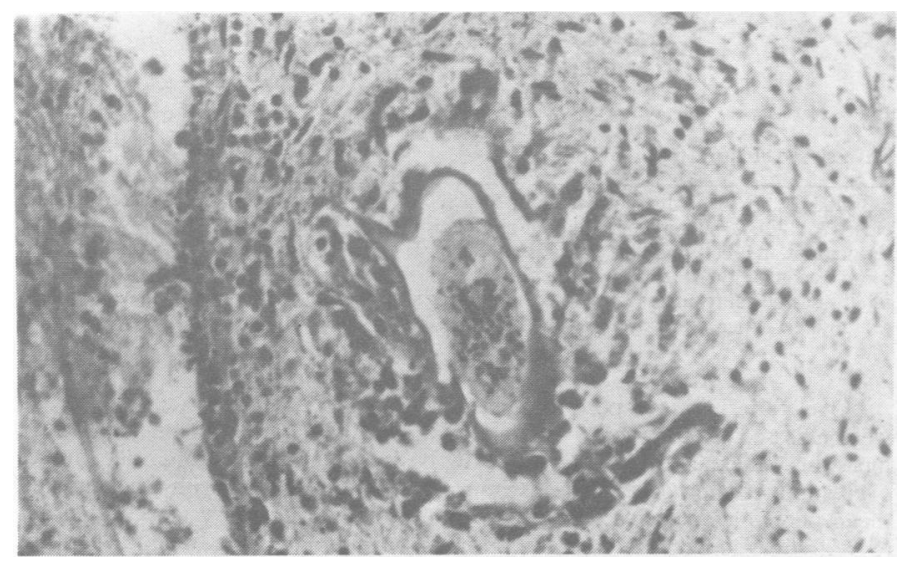

Schistosoma mansoni ovum. for Egyptian (schistosomal) splenomegaly. In addition, he was found to have iron deficiency anaemia (haemoglobin concentration $11 \cdot 2 \mathrm{~g} / \mathrm{l}$ ). After nasogastric intubation and fluid replacement (including 1 unit of blood) laparotomy was performed through a paramedian incision. There were some 3 litres of haemorrhagic ascites and a gangrenous segment of jejunum $76 \mathrm{~cm}$ long. There was a clear cut line of demarcation between the viable and non-viable bowel but no constriction ring and nothing to suggest previous entrapment of the loop. Thrombosis was observed in the small mesenteric veins draining the affected segment, but the major mesenteric and splenic veins were all patent. The liver and colon seemed normal.

After resection of the gangrenous small bowel with end to end anastomosis the patient recovered and was discharged home 12 days later. Histological examination showed thrombosis of medium sized mesenteric veins and arteries, which contained numerous ova of $S$ mansoni type. There was coagulative necrosis of the resected bowel but no evidence of arteritis or any other underlying cause for vascular occlusion.

\section{Comment}

The pathological lesions of schistosomiasis result from the deposition of a large number of live ova.in the serosal and submucosal layers of the intestine. Enzymatic digestion of the tissues provokes a chronic inflammatory response, characterised by ulceration and thickening of the mucosa, which may accumulate to form polyps. ${ }^{23}$ Symptoms include abdominal colic, diarrhoea, rectal passage of blood and mucus, and allergy like reactions, such as fever and urticaria. Though children may develop acute dysentery, emergency presentation is unusual in adults. We are not aware of any reports of acute mesenteric ischaemia as a complication of schistosomiasis. Nevertheless, our patient showed no evidence of any other condition known to be associated with mesenteric ischaemia secondary to occlusive disease of the small vessels, in particular atherosclerosis, Buerger's disease, embolism, and autoimmune disease. Vasculitis was excluded by the histological findings, and there was no relevant drug history. ${ }^{45}$ The finding of many parasitic ova in the thrombosis in the mesenteric vessels supports our diagnosis.

We thank Professor R C N Williamson and Mr M I Aldoori, Department of Surgery, Bristol Royal Infirmary, for reading the manuscript.

1 Iyer HV, Abaci BF, Rehnke EC, et al. Intestinal obstruction due to schistosomiasis. Am f Surg 1985;149:409-11.

2 Cheng TC. General parasitology. 1st ed. New York, London: Academic Press, 1974:423.

3 Binford C, Conner DH. Schistosomiasis. In: Pathology of tropical and extraordinary diseases. Vol 2. 2nd ed. Kent: Castle House Publications, 1979:495.

4 Symmers WSTC. Systemic pathology. Vol 3. 2nd ed. Edinburgh: Churchill Livingstone, 1978: 1063. 5 Schwartz SI. Principles of surgery. 4th ed. New York: McGraw Hill Book Company, 1984:1433.

(Accepted 19 January 1987)

Al Mustansiriyah University and Medical College, PO Box 14132, Baghdad, Iraq

S ANAYI, MB, FRCSED, senior lecturer, department of surgery

N AL-NASIRI, MB, MRCPATH, assistant professor, department of pathology

Correspondence to: Mr Anayi.

\section{Bronchoconstrictor properties of preservatives in ipratropium bromide (Atrovent) nebuliser solution}

The original formulation of ipratropium bromide nebuliser solution (Atrovent) caused paradoxical and severe bronchoconstriction in some asthmatic patients. We showed that this response was due to hypotonicity of the original solution, ${ }^{1}$ and as a consequence it was reformulated to render it isotonic. Recently, however, bronchoconstriction after inhalation of isotonic ipratropium bromide solution has also been reported. As well as containing the active ingredient ipratropium bromide, Atrovent also contains benzalkonium chloride $(0.25 \mathrm{~g} / \mathrm{l})$ and edetic acid (EDTA) $(0.5 \mathrm{~g} / \mathrm{l})$. We investigated the role of these additives in causing bronchoconstriction.

\section{Patients, methods and results}

Twenty two subjects with stable asthma (10 women, 12 men, mean (SEM) age 41 (3) years) whose airways response to isotonic Atrovent nebuliser solution had not been determined were studied. All patients initially attended the laboratory to inhale $4 \mathrm{ml}$ isotonic Atrovent followed by measurement of forced expiratory volume in one second $\left(F E V_{1}\right)$ for up to 60 minutes. Those in whom the FEV 1 fell 